\title{
Relationship between pathogenicity, race and vegetative compatibility grouping among Algerian populations of Fusarium oxysporum f. sp. pisi causing pea wilt
}

\author{
Aoumria Merzoug*, Lakhdar Belabid \\ Laboratory of Research on Biological Systems and Geomatics (LRSBG), Department of Agronomy, \\ University of Mascara, Mascara, Algeria
}

Vol. 57, No. 4: 370-378, 2017

DOI: 10.1515/jppr-2017-0051

Received: July 17, 2017

Accepted: November 9, 2017

${ }^{*}$ Corresponding address: merzougaoumria@hotmail.com

\begin{abstract}
Fusarium oxysporum f. sp. pisi (FOP) is a significant and destructive pathogen of field pea in Algeria. In the present study, 50 isolates of F. oxysporum f. sp. pisi, the causal agent of pea (Pisum sativum) wilt, collected from different parts of western Algeria and representing four races of the pathogen, were analyzed for virulence. The wilt incidence ranged from 6.66 to $88.33 \%$ on a highly susceptible cultivar (Little Marvel). Twenty-one isolates belonging to four races of FOP and one nonpathogenic F. oxysporum (FO) isolate were analyzed for vegetative compatibility in order to reveal the genetic structure of the population and to check the reliability of the method for the identification of physiological races of FOP. Obtained results showed that the FOP isolates could be classified into four main vegetative compatibility groups (VCGs) that corresponded to races 1, 2A, 2B and 5. The race 6 isolate fell into the race 1 VCG. To our knowledge, this is the first such study in Algeria of its kind.
\end{abstract}

Key words: Fusarium oxysporum f. sp. pisi, nit mutants, pathogenicity, pea wilt, physiologic races, vegetative compatibility group

\section{Introduction}

Fusarium oxysporum f. sp. pisi (FOP), the causal organism of pea wilt, occurs as a number of races identified by tests on differential hosts of pea. So far, four races: 1, 2, 5 and 6, have been distinguished. Races 1, 2 and 6 have been reported in Europe, while all four races are found in the USA (Haglund and Kraft 2001) and in Algeria (Merzoug et al. 2014). The pathogenicity test to determine the race of an isolate is time-consuming and greatly affected by environmental conditions. In the absence of a sexual stage another way of grouping Fusarium isolates was proposed, based on their ability to form heterokaryons by anastomosis. Vegetative compatibility groups (VCGs) in fungi are a genetictrait controlled by vic or het loci and identical alleles at each loci must be present in two compatible hyphae before anastomosis takes place (Leslie 1993). Vegetatively compatible isolates of a fungal species are placed in the same VCG. Isolates within the same VCG often share common biological, physiological, and pathological characteristics. VCGs are identified by using nitrate nonutilizing (nit) auxotrophic mutants that show thin but expansive growth on minimal medium with nitrate as sole nitrogen source. Isolates are considered vegetatively compatible when they complement nit mutants anastomose and produce wild type growth $(\mathrm{Pu}-$ halla 1985). That exchange of genetic material would be limited to compatible isolates within a VCG and so each VCG represents a genetically isolated population. Vegetative compatibility has been used to classify isolates of F. oxysporum belonging to distinct formal specials (Klein et al. 2005), races within a special form (Elena and Pappas 2006) and special forms and/or races within or between different geographical origins (Di Primo et al. 2002; Pasquali et al. 2005). VCG has 
been used to distinguish between nonpathogenic and pathogenic populations on the same host species (Lori et al. 2004). In general, pathogenic isolates of F. oxysporum in the same VCG are assumed to be associated with the same clonal lineage, even if they are geographically isolated (Leslie 1993). However, isolates belonging to different VCGs can also belong to the same clonal lineage (Baayen et al. 2000). Several formae speciales of F. oxysporum have been characterized by VCG analysis (Lori et al. 2004; Abo et al. 2005), as well as by random amplified polymorphic DNA (RAPD) analysis (Alves-Santos et al. 2007; Bayraktar et al. 2008; Baysal et al. 2010) and several studies have combined both markers (Vakalounakis et al. 2004; Nagarajan et al. 2006). This technique is appropriate for developing countries with inadequate facilities for molecular work and can rapidly determine genetic groups of many fungal pathogens and their relation to pathogenicity (Cumagun et al.2008). The objective of this work was to determine VCGs in a collection of 21 isolates of different pathogenic races $F$. oxysporum f. sp. pisi from different geographical origins in four different agro-climatic zones in western Algeria (coastal plains, interior plains, the high plateaus, and the Sahara) and compatibility between pathogenic and nonpathogenic F. oxysporum isolates obtained from asymptomatic pea rhizospheres.

\section{Materials and Methods}

\section{Fungal isolates}

The study was conducted with 50 isolates representing the four races of FOP collected from different regions of western Algeria (Table 1). Pathogenicity tests were performed on the standard pea differential cultivars. The inoculum production and inoculation method have been previously described (Merzoug et al. 2014). Twenty-one isolates of different pathogenic races F. oxysporum f. sp. pisi and one nonpathogenic isolate (np) were selected for vegetative compatibility tests. The choice of this population was based on pathogenicity, races and areas. The isolates were maintained as single-spore colonies in tubes with potato dextrose agar (PDA), at $4^{\circ} \mathrm{C}$. The isolates selected for the tests are listed in Table 2.

\section{Vegetative compatibility tests}

\section{Culture media}

The media used in the vegetative compatibility study were PDA with $1.5 \%$ chlorate (PDC), salt minimal medium with $1.5 \%$ chlorate (MMC), minimal medium (MM) with nitrate, chlorate, nitrite and hypoxanthine added according to Puhalla (1985) and Correll et al. (1987).

\section{Determination of VCGs}

Selection, characterization and storage of nit mutants Vegetative compatibility groups were determined through the complementation of nitrate nonutilizing (nit) mutants as a visual indicator of heterokaryon formation (Puhalla 1985). Generation, isolation and characterization of nit mutants were carried out according to the methodology of Correll et al. (1987). The nit mutants were selected by Puhalla's method (Puhalla 1985). For this, $2 \mathrm{~mm}$ PDA blocks with fungal mycelium were transferred to $9 \mathrm{~cm}$ plates that contained $\mathrm{PDC}$ or $\mathrm{MMC}$ (Puhalla 1985), and were incubated at $25^{\circ} \mathrm{C}$ for 1 to 3 weeks. Fast growing sectors were transferred to minimal medium (MM) and those which grew as fine and expanding colonies, without aerial mycelium, were considered to be nit mutants. In cases where we were not able to select mutants under the conditions described above, we introduced some modifications, in order to increase the chlorate concentration in MMC or PDC up to 5\%, or two cultures consecutive on MMC $(1.5 \%)$ chlorate. Changes were inspired by the methodology described by Nogales Moncada et al. (2009).

\section{Phenotype identification}

Nit mutants were grown on basal medium amended with different nitrogen sources: sodium nitrate, sodium nitrite and hypoxanthine. Petri dish cultures were incubated under the previously described conditions and examined after 5 days for mutant identification. Based on an ability to grow on the different nitrogen sources, three types of mutants were easily identified. Nit1 mutants were mutated in a structural locus of nitrate reductase. Those mutants did not grow with nitrate as the only nitrogen source, but they did grow in the presence of nitrite or hypoxantine. Nit3 mutants were mutated in a locus which was probably involved in the regulation of both nitrate reductase and nitrite reductase. Consequently, these mutants did not grow with nitrate or nitrite as the only nitrogen source, but they did grow in the presence of hypoxanthine. Lastly, nitM mutants were mutated in one of the loci which were involved in the synthesis of the molybdenum co-factor, which is necessary for both the reduction of nitrate and the hydroxylation of hypoxanthine. These mutants cannot grow on nitrate or hypoxanthine as the only nitrogen source, but they will grow on nitrite (Correll et al. 1987).

\section{Complementary tests}

Vegetative compatibility was determined on the basis of the formation of heterokaryons in the contact area between the two colonies, as shown by the growth of aerial mycelium similar to that of the wild colony. 
Table 1. Place of origin, races and wilt incidence of Fusarium oxysporum f. sp. pisi isolates

\begin{tabular}{|c|c|c|c|c|c|}
\hline \multirow{2}{*}{ No. } & \multirow{2}{*}{ Geographic origin } & \multirow{2}{*}{ Departments } & \multirow{2}{*}{$\begin{array}{l}\text { Isolates } \\
\text { codes }\end{array}$} & \multicolumn{2}{|c|}{ Pathogenicity } \\
\hline & & & & wilt incidence [\%] & races \\
\hline 1 & & Ain Temouchent & Fop A1 & $58.33 \mathrm{~b}$ & 1 \\
\hline 2 & & Ain Temouchent & Fop A2 & $56.66 \mathrm{~b}$ & 1 \\
\hline 3 & & Ain Temouchent & Fop A16 & $25.66 d$ & 6 \\
\hline 4 & & Ain Temouchent & Fop A18 & $21.00 \mathrm{~d}$ & 2 \\
\hline 5 & & Ain Temouchent & Fop A19 & $26.66 d$ & 1 \\
\hline 6 & Coastal plains & Ain Temouchent & Fop A21 & $36.33 c$ & 5 \\
\hline 7 & & Ain Temouchent & Fop A22 & $41.33 c$ & 6 \\
\hline 8 & & Mostaganem & Fop M42 & $36.66 c$ & 5 \\
\hline 9 & & Mostaganem & Fop M43 & $38.00 \mathrm{c}$ & 2 \\
\hline 10 & & Mostaganem & Fop M44 & $45.00 c$ & 1 \\
\hline 11 & & Mostaganem & Fop M45 & $40.33 c$ & 1 \\
\hline 12 & & Tlemcen & Fop TL24 & $25.66 \mathrm{~d}$ & 6 \\
\hline 13 & & Tlemcen & Fop TL27 & $56.33 \mathrm{~b}$ & 1 \\
\hline 14 & & Tlemcen & Fop TL28 & $60.00 \mathrm{~b}$ & 6 \\
\hline 15 & & Tlemcen & Fop TL29 & $71.66 b$ & 1 \\
\hline 16 & & Tlemcen & Fop TL31 & $69.66 b$ & 1 \\
\hline 17 & & Tlemcen & Fop TL32 & $69.00 \mathrm{~b}$ & 1 \\
\hline 18 & & Chlef & Fop C20 & $78.00 \mathrm{~b}$ & 1 \\
\hline 19 & & Chlef & Fop C21 & $63.33 \mathrm{~b}$ & 1 \\
\hline 20 & & Relizane & Fop R17 & $60.00 \mathrm{~b}$ & 1 \\
\hline 21 & & Relizane & Fop R26 & $70.00 \mathrm{~b}$ & 2 \\
\hline 22 & & Relizane & Fop R27 & $46.66 c$ & 1 \\
\hline 23 & & Relizane & Fop R28 & $43.33 c$ & 1 \\
\hline 24 & Interior plains & Relizane & Fop R29 & $83.33 \mathrm{a}$ & 1 \\
\hline 25 & & Relizane & Fop R31 & $66.66 \mathrm{~b}$ & 1 \\
\hline 26 & & Relizane & Fop R32 & $63.33 \mathrm{~b}$ & 6 \\
\hline 27 & & Mascara & Fop Ma6 & $60.66 \mathrm{~b}$ & 2 \\
\hline 28 & & Mascara & Fop Ma9 & $46.66 c$ & 2 \\
\hline 29 & & Mascara & Fop Ma13 & $60.33 b$ & 1 \\
\hline 30 & & Mascara & Fop Ma15 & $60.66 \mathrm{~b}$ & 2 \\
\hline 31 & & Mascara & Fop Ma19 & $65.00 \mathrm{~b}$ & 1 \\
\hline 32 & & Sidi Belabes & Fop Sb1 & $86.66 \mathrm{a}$ & 1 \\
\hline 33 & & Sidi Belabes & Fop Sb3 & $60.00 \mathrm{~b}$ & 2 \\
\hline 34 & & Sidi Belabes & Fop Sb4 & $62.33 \mathrm{~b}$ & 1 \\
\hline 35 & & Sidi Belabes & Fop Sb11 & $67.00 \mathrm{~b}$ & 1 \\
\hline 36 & & Sidi Belabes & Fop Sb14 & $66.66 \mathrm{~b}$ & 1 \\
\hline 37 & & Tiaret & Fop T46 & $35.00 \mathrm{c}$ & 1 \\
\hline 38 & & Tiaret & Fop T47 & $40.00 c$ & 2 \\
\hline 39 & & Tiaret & Fop T48 & $23.33 \mathrm{~d}$ & 1 \\
\hline 40 & & Tiaret & Fop T49 & $50.00 c$ & 6 \\
\hline 41 & High plateaus & Tiaret & Fop T50 & $44.33 c$ & 1 \\
\hline 42 & & Tiaret & Fop T51 & $39.00 c$ & 1 \\
\hline 43 & & Tiaret & Fop T52 & $40.00 c$ & 1 \\
\hline 44 & & Saida & Fop S56 & $88.33 \mathrm{a}$ & 1 \\
\hline 45 & & Saida & Fop S58 & $34.33 c$ & 1 \\
\hline 46 & & Adrar & Fop Ad60 & $6.66 \mathrm{e}$ & $\mathrm{np}$ \\
\hline 47 & & Adrar & Fop Ad67 & $88.33 a$ & 2 \\
\hline 48 & Sahara & Adrar & Fop Ad62 & $60.00 \mathrm{~b}$ & 2 \\
\hline 49 & & Adrar & Fop Ad63 & $68.33 \mathrm{~b}$ & 1 \\
\hline 50 & & Adrar & Fop Ad66 & $48.33 c$ & 1 \\
\hline
\end{tabular}


Table 2. Number of each nit mutant type selected on characterization media in relation to geographic origin

\begin{tabular}{|c|c|c|c|c|c|c|c|}
\hline $\begin{array}{l}\text { Geographic } \\
\text { origin }\end{array}$ & Department & Isolates & Race & nit1 & nit3 & nitM & Total \\
\hline & Ain Temouchent & $\mathrm{A} 2$ & 1 & $10(100 \%)^{*}$ & $0(0 \%)$ & $0(0 \%)$ & 10 \\
\hline & Ain Temouchent & $\mathrm{A} 21$ & 5 & $10(41.66 \%)$ & $8(33.33 \%)$ & $6(25 \%)$ & 24 \\
\hline \multirow[t]{8}{*}{ Coastal plains } & Ain Temouchent & $\mathrm{A} 22$ & 6 & $8(66.66 \%)$ & $0(0 \%)$ & $4(33.33 \%)$ & 12 \\
\hline & Mostaganem & M42 & 5 & $9(69.23 \%)$ & $0(0 \%)$ & 4 (30.76\%) & 13 \\
\hline & Mostaganem & M44 & 1 & $11(45.83 \%)$ & $1(4.16 \%)$ & $12(50 \%)$ & 24 \\
\hline & Tlemcen & TI 24 & 6 & 7 (58.33\%) & $0(0 \%)$ & $5(41.66 \%)$ & 12 \\
\hline & Tlemcen & T127 & 1 & $13(86.66 \%)$ & $0(0 \%)$ & $2(13.33 \%)$ & 15 \\
\hline & Tlemcen & $\mathrm{T} \mid 28$ & 6 & $16(88.8 \%)$ & $0(0 \%)$ & $2(11.11 \%)$ & 18 \\
\hline & Chlef & $\mathrm{C} 20$ & 1 & $6(60 \%)$ & $2(20 \%)$ & $2(20 \%)$ & 10 \\
\hline & Cheliff & $\mathrm{C} 21$ & 1 & $6(54.5 \%)$ & $1(9 \%)$ & $4(36.3 \%)$ & 11 \\
\hline \multirow[t]{7}{*}{ Interior plains } & Relizane & $\mathrm{R} 26$ & 2 & $11(100 \%)$ & $0(0 \%)$ & $0(0 \%)$ & 11 \\
\hline & Relizane & $\mathrm{R} 28$ & 1 & $2(20 \%)$ & $2(20 \%)$ & $6(60 \%)$ & 10 \\
\hline & Mascara & Ma13 & 1 & $14(63.6 \%)$ & $0(0 \%)$ & $8(36.36 \%)$ & 22 \\
\hline & Mascara & Ma15 & 2 & 7 (35\%) & $7(35 \%)$ & $6(30 \%)$ & 20 \\
\hline & Sidi Belabes & Sb1 & 1 & $8(88.8 \%)$ & $1(11.1 \%)$ & $0(0 \%)$ & 9 \\
\hline & Sidi Belabes & Sb11 & 1 & $12(46.15 \%)$ & $0(0 \%)$ & 14 (53.84\%) & 26 \\
\hline & Tiaret & T49 & 6 & $5(21.73 \%)$ & $16(69.56 \%)$ & 2 (8.69\%) & 23 \\
\hline \multirow[t]{3}{*}{ High plateaus } & Tiaret & T51 & 1 & 2 (9.09\%) & $4(18.18 \%)$ & 16 (72.72\%) & 22 \\
\hline & Saida & S58 & 1 & $5(33.33 \%)$ & $5(33.33 \%)$ & $5(33.33 \%)$ & 15 \\
\hline & Adrar & Ad62 & 2 & $6(60 \%)$ & $0(0 \%)$ & $4(40 \%)$ & 10 \\
\hline \multirow[t]{3}{*}{ Sahara } & Adrar & Ad63 & 1 & $10(83.33 \%)$ & $0(0 \%)$ & $2(16.66 \%)$ & 12 \\
\hline & Adrar & Ad60 & $\mathrm{np}$ & $2(14.28 \%)$ & $10(71.42 \%)$ & $2(14.28 \%)$ & 14 \\
\hline & Total & & 22 & $180(52.47 \%)$ & 57 (16.41\%) & 106 (30.9\%) & 343 \\
\hline
\end{tabular}

*percentage of isolates in that group; $\mathrm{np}$ - nonpathogenic F. oxysporum

A portion of the nitM colony was placed in the middle of the culture dish containing MM, and one portion each of nit 1 and nit 3 mycelium from other strains was placed at an equal distance from the nitM colony. Complementation between nit1 and nit3 mutants occurs less frequently than complementation between one of these mutants with a nitM mutant. Each nitM was paired with a nit 1 and a nit 3 from other strains in all possible combinations. All pairings were replicated twice. The complementation test was considered: negative - when there was no prototrophic growth in the mycelial line of contact; weak - when interaction became evident by the appearance of a thin, sometimes noncontinuous, zone of prototrophic growth with very little aerial mycelium; strong - when a dense line of prototrophic growth with abundant aerial mycelium was obtained. Weak and strong reactions were taken as evidence of compatibility. Training the heterokaryon, visible by the appearance of a thick, dense aerial mycelium, was noted after 5, 10, 15, 25 days and up to 4 weeks.

\section{Statistical analysis}

The results were subjected to statistical analysis. All the collected data were submitted to ANOVA analysis using Statistica software v. 5.5 (Statsoft, Ed'99) and Biostat 2009 and the significance of differences among treatments was recorded at $\mathrm{p}<0.05$. Multiple comparisons of the means were conducted according to the Newman-Keuls test at $\mathrm{p}<0.05$.

\section{Results}

Results of percentage wilt incidence of 50 isolates of F. oxysporum f. sp. pisi collected from different parts of western Algeria and representing four races of the pathogen ranged from 6.66 to $88.33 \%$ on the highly susceptible cultivar (Little Marvel) (Table 1). A partial account of this work has previously been published (Merzoug et al. 2014). 


\section{Isolation, characterization and storage of nit mutants}

The medium PDC was selected, that proved most favorable to the growth of mutants sectors. Isolation of chlorate-resistant mutants and phenotypic diversity of nit mutants were obtained from all FOP isolates, but there was considerable variation in their recovery rate. Whenever possible, at least two different nit mutants, preferably a nit 1 and a nitM, were selected and stored as indicated in Materials and Methods.

\section{Vegetative compatibility tests}

The results of the characterization of 343 chlorate-resistant mutants (Table 2), indicate that in $180(52.47 \%)$ of them are nit1, 106 (30.9\%) nitM and 57 (16.41\%) nit3. The overall distribution of three types of nit mutant according to the races, shows that race 1 forms the greatest number of mutants with a total of $186(54.22 \%)$, which represents more than half of all the mutants followed by race 6 with 65 (18.95\%). The highest number of mutants nit 1 was obtained from race 1 with 99 (55\%). Race 2 had the lowest number of mutants nit3 with 7 (12.28\%) (Table 3).

\section{Development of the pairs of mutants}

When possible, a nit 1 and a nitM mutant from each isolate were selected and paired in all possible combinations. The positive complementarity between different nit mutants resulted in the growth of aerial mycelium in the confrontation zone, resulting from the anastomosis hyphae matched mutant colonies. In this study, the line of fusion of the hyphae varied in its density and appeared 10-15 days after transfer of cuttings on the MM medium. It consisted of a continuous growth line of thick and abundant mycelium, or as a weak aerial mycelium line dispersed and a more or less dense or a less defined line separated with a mycelium +/- flush that appeared after 15 days up to a month (Fig. 1). The results of various comparisons between nit mutants complementary to a same isolate were self-compatible for all isolates tested except for two isolates of race 1 ( $\mathrm{Sb} 1$ and $\mathrm{A} 2$ ) and an isolate of race 2 (R26) which was self-incompatible knowing that for the three isolates only nit1 was obtained. The nonpathogenic isolate was self-compatible.

\section{Vegetative compatibility group (VCG)}

Analysis of results of the complementation test listed in Table 4 shows:

1. Race 2 isolates were classified into 2 subgroups, the Ma15 isolate was self-compatible but incompatible with all other isolates of race 2. Isolate R26 was self-incompatible but it was compatible with isolate Ad62. These 2 isolates had distant geographical origins (internal plains and Sahara) while Ma15 and R26 which were incompatible had the same geographical origin.

2. Race 5 isolates were classified in the same VCG. They were compatible with each other and showed a slowcomplementation that occurred aftera month of confrontation with isolates of race 1 (Sb1, Ad63, S58, C24 and A2). The only positive complementation was observed between M44 and M42, which were from the same region (Mostaganem).

3. Race 1 isolates were classified in the same VCG. All isolates were self-compatible with the exception of $\mathrm{Sb} 1$ and A2 isolates which were self-incompatible and formed only nit 1 that produce a negative or inconclusive complementation. Compatibility relationships within the race 1 VCG are not simple. The reaction of compatibility between isolates was variable. For example, the Sb1 isolate was only compatible with the TL27 and had a weak reaction with R28, while TL27 was compatible with all isolates of race 1 with the exception of S58. Ma13 was compatible with TL27 but not compatible with Sb1.

4. Race 6 isolates were classified in the same VCG as race 1 . Race 6 isolates were all self-compatible. Complementation was positive or partial between most isolates of race 6.

5. The nonpathogenic isolate (np) was self-compatible. It was compatible with race 1 and race 6 isolates but was incompatible with the R2 races and race 5 isolates.

There was no compatibility between the VCGs that comprised races $2 \mathrm{~A}$ and $2 \mathrm{~B}$ and any other VCGs. However, there was a weak interaction between some race 1 and race 5 isolates, although these interactions only developed after at least 4 weeks incubation (Table 5).

The results obtained show that the FOP isolates from western Algeria can be classified into four main VCGs that corresponded to races $1,2 \mathrm{~A}, 2 \mathrm{~B}$ and 5 . The race 6 isolate, fell into the race 1 VCG, and although compatibility was not complete with any race 1 isolate tested. In addition, after several weeks of incubation there was also weak compatibility to some race 5 isolates. According to the procedure for determining the VCG described by Correll (1991) and the systematic numbering proposed by Katan and Katan (1999). The VCGs FOP code number is 0070-0073.

\section{Discussion}

In this study, virulence and vegetative compatibility were analyzed for FOP isolates representing four races prevalent in the west of Algeria. The range of wilt 
Table 3. Distribution of numbers and percentages mutants (nit) according to the different physiological races of Fusarium oxysporum f. sp. pisi

\begin{tabular}{lcccccr}
\hline Nit mutant & R1 & R2 & R5 & R6 & np & Total \\
\hline nit1 & $99(55 \%)^{*}$ & $24(13.3 \%)$ & $19(10.5 \%)$ & $36(20 \%)$ & $2(1.1 \%)$ & 180 \\
nit3 & $16(28 \%)$ & $7(12.28 \%)$ & $8(14.03 \%)$ & $16(28 \%)$ & $10(17.5 \%)$ & 57 \\
nitM & $71(66.98 \%)$ & $10(9.43 \%)$ & $10(9.43 \%)$ & $13(12.26 \%)$ & $2(1.88 \%)$ & 106 \\
Total & $186(54.22 \%)$ & $41(11.95 \%)$ & $37(10.78 \%)$ & $65(18.95 \%)$ & $14(4.08 \%)$ & 343 \\
\hline
\end{tabular}

$\mathrm{np}$ - nonpathogenic F. oxysporum; *percentage of isolates in that group
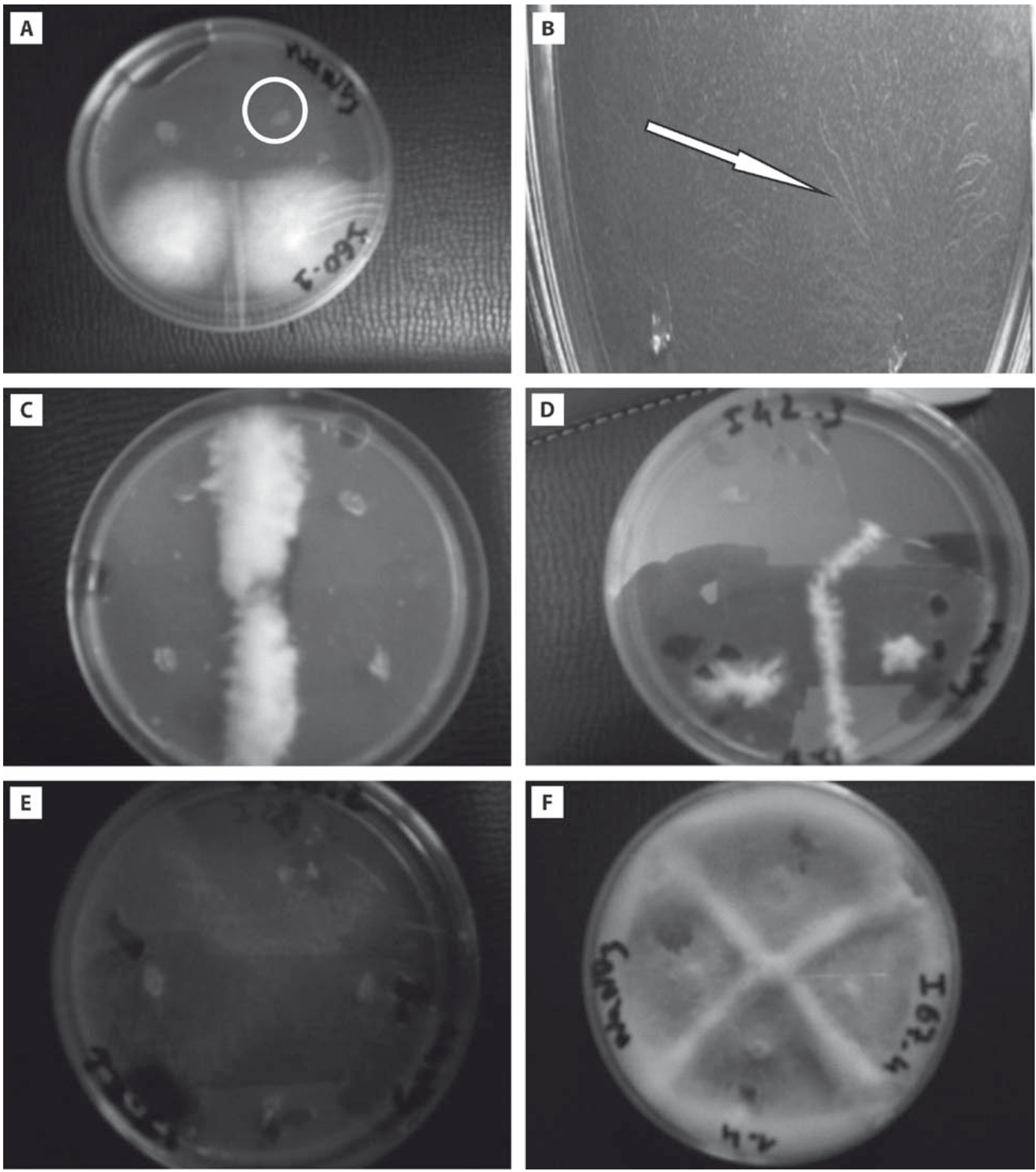

Fig. 1. Vegetative compatibility tests. A-B - growth of nit mutants on minimal medium (MM). The elliptical areas - the chlorateresistant sectors; the arrow - development of thin mycelium. Pairing of nit mutants subcultured on $\mathrm{MM} ; \mathrm{C}$ - continuous growth line of a thick and abundant aerial mycelium; D - weak aerial mycelium line dispersed; $\mathrm{E}$ - less defined line separates with a mycelium +/flush, that appears after a month; F - self-compatibility (np isolate Ad67) 
Table 4. Vegetative compatibility relationships between race isolates of Fusarium oxysporum f. sp. pisi

\begin{tabular}{|c|c|c|c|c|c|c|c|c|c|c|c|c|c|c|c|c|c|c|c|c|c|c|c|}
\hline \multirow{2}{*}{ 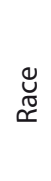 } & \multicolumn{4}{|c|}{ R2 } & \multicolumn{2}{|c|}{ R5 } & \multicolumn{4}{|c|}{ R6 } & \multicolumn{13}{|c|}{$\mathrm{R} 1$} \\
\hline & isolates & $\frac{\stackrel{n}{\frac{\pi}{\sigma}}}{\sum^{\frac{\pi}{2}}}$ & $\frac{\widetilde{0}}{2}$ & $\underset{\sim}{\check{\sim}}$ & $\stackrel{\mathcal{N}}{\Sigma}$ & $\overline{\frac{\pi}{\alpha}}$ & $\underset{g}{\stackrel{g}{f}}$ & $\stackrel{\stackrel{\infty}{N}}{F}$ & $\stackrel{\mathbb{N}}{\stackrel{D}{F}}$ & $\underset{\leftarrow}{\mathbb{x}}$ & 음 & $\overline{\overline{0}}$ & $\stackrel{\widehat{~}}{F}$ & $\frac{n 0}{0}$ & 串 & $\frac{m}{\frac{m}{\pi}}$ & ิㅗ & $\underset{x}{2}$ & $\stackrel{\bar{n}}{F}$ & $\stackrel{\&}{\&}$ & $\stackrel{\stackrel{\sim}{\sim}}{\underset{\sim}{x}}$ & $\overline{\mathrm{U}}$ & $\frac{8}{8}$ \\
\hline \multirow{3}{*}{$\mathrm{R} 2$} & Ma15 & + & - & - & - & - & - & - & - & - & - & - & - & - & - & - & - & - & - & - & - & - & - \\
\hline & Ad62 & & + & + & - & - & - & - & - & - & - & - & - & - & - & - & - & - & - & - & - & - & - \\
\hline & $\mathrm{R} 26$ & & & - & - & - & - & - & - & - & - & - & - & - & - & - & - & - & - & - & - & - & - \\
\hline \multirow{2}{*}{ R5 } & M42 & & & & + & + & - & - & - & - & - & - & - & $+/-$ & $+/-$ & - & - & $+/-$ & - & + & - & - & - \\
\hline & $\mathrm{A} 21$ & & & & & + & - & - & - & - & - & - & - & $+/-$ & - & - & $+/-$ & $+/-$ & - & - & - & - & - \\
\hline \multirow{4}{*}{ R6 } & T49 & & & & & & + & + & $+/-$ & $+/-$ & - & - & + & $+/-$ & $+/-$ & + & - & + & - & + & - & + & + \\
\hline & TI28 & & & & & & & + & $+/-$ & + & - & + & - & - & + & $+/-$ & - & $+/-$ & - & + & - & $+/-$ & $+/-$ \\
\hline & $\mathrm{T} 124$ & & & & & & & & + & + & - & - & + & - & $+/-$ & - & + & - & $+/-$ & - & - & - & + \\
\hline & $\mathrm{A} 22$ & & & & & & & & & + & - & - & - & - & - & - & + & - & + & + & - & - & - \\
\hline \multirow{12}{*}{$\mathrm{R} 1$} & $\mathrm{Sb} 1$ & & & & & & & & & & - & - & + & - & - & - & - & - & - & - & $+/-$ & - & $+/-$ \\
\hline & Sb11 & & & & & & & & & & & $+/-$ & - & - & - & + & $+/-$ & - & - & - & $+/-$ & - & + \\
\hline & $\mathrm{T} 127$ & & & & & & & & & & & & $+/-$ & $+/-$ & - & + & + & + & + & + & + & + & + \\
\hline & Ad63 & & & & & & & & & & & & & + & $+/-$ & - & + & - & + & + & + & $+/-$ & + \\
\hline & S58 & & & & & & & & & & & & & & + & - & + & - & + & + & $+/-$ & - & + \\
\hline & Ma13 & & & & & & & & & & & & & & & + & - & - & $+/-$ & + & - & - & $+/-$ \\
\hline & C20 & & & & & & & & & & & & & & & & + & - & $+/-$ & + & - & $+/-$ & + \\
\hline & $\mathrm{A} 2$ & & & & & & & & & & & & & & & & & - & $+/-$ & + & $+/-$ & - & $+/-$ \\
\hline & TI51 & & & & & & & & & & & & & & & & & & + & - & + & - & $+/-$ \\
\hline & M44 & & & & & & & & & & & & & & & & & & & + & + & + & $+/-$ \\
\hline & $\mathrm{R} 28$ & & & & & & & & & & & & & & & & & & & & $+/-$ & - & + \\
\hline & $\mathrm{C} 21$ & & & & & & & & & & & & & & & & & & & & & + & $+/-$ \\
\hline $\mathrm{np}$ & Ad60 & & & & & & & & & & & & & & & & & & & & & & + \\
\hline
\end{tabular}

"+"- compatible interaction; "-" - incompatible interaction; "+/-" - partially compatible interaction; np - nonpathogenic F. oxysporum

Table 5. Correlation between vegetative compatibility groups (VCG) and races

\begin{tabular}{ccccccc}
\hline Race & R1 & R2A & R2B & R5 & R6 & $\mathrm{np}$ \\
\hline R1 & + & - & - & $+/-$ & + & + \\
R2A & & + & - & - & - & - \\
R2B & & & $+/-$ & - & - & - \\
R5 & & & + & - & - \\
R6 & & & & + & + \\
NP & & & & & + \\
\hline+ " - compatible interaction; "-" - incompatible interaction; "+/-" \\
- partially compatible interaction; np- nonpathogenic F. oxysporum
\end{tabular}

incidence $(6.33-88.33 \%)$ caused by the isolates showed variability in the virulence of the pathogen even on a single susceptible variety of pea. In the present work, the three types of mutant's nit whose highest percentage is the nit 1 followed by nitM and the lower the nit3 without these differences may be related to a specific characteristic of isolates (geographical origin, race or virulence). According to Bowden and Leslie (1992) and Puhalla (1985), the frequency of nit1 mutants is higher than the frequency of the other types of nit mutants. The percentage of nit3 is always lower (Belabid and Fortas 2002). The study of the organization of 21 isolates in the formae speciales pisi from different geographical origins (western Algeria) and belonging to the four races of FOP showed the existence of four VCGs, reflecting its genetic diversity. Such diversity has been reported for many formae speciales, such as F. oxysporum f. sp. radicis-lycopersici (Katan and Katan 1999), F. oxysporum f. sp. ciceris (Nogales Moncada et al. 2009) and F. oxysporum f. sp. batatas (RodriguezMolina et al. 2013). Comparing the VCG distribution and race distribution defined by means of differential hosts, showed that isolates which belong to different races are included in the same VCG (Saabale and Dubey 2014). This is the case of the isolates of race 1 and 6 F. oxysporum f. sp. pisi which are in the same VCG, whereas isolates of race 2 are included in two other VCGs. This situation is found in other formae speciales for which the VCG-race relationships are complex. Indeed, it is known that more than one race may appear in the same VCG and the same race may contain more than one VCG (Correll 1991). A similar degree of complexity has been noted in the F. oxysporum f. sp. cubense (Somrith et al. 2011), many of which belong to the same race and multiple VCGs correspond to a single race. It is the same for F. oxysporum f. sp. 
lycopersici (Katan and Katan 1999) and F. oxysporum f. sp. melonis (Elena and Pappas 2006).

The results of the weak or partial vegetative compatibility observed between isolates of races 1 and 5 suggest a higher degree of similarity with isolates of race 1 than of races $2 \mathrm{~A}$ and $2 \mathrm{~B}$. According to Whitehead et al. (1992), it seems likely that races 5 and 6 derived from race 1 . The greatest degree of intra-racial variation seen among race 1 isolates may suggest that this is the oldest race. The differences between races 1 and 5 compared to the similarity between races 1 and 6 would indicate that race 6 may have evolved much more recently than race 5 . Race 2 is very different from races 5, 6 and 1 and may have a distinct evolutionary origin. Races $2 \mathrm{~A}$ and $2 \mathrm{~B}$ are clearly very closely related, but the total lack of vegetative compatibility between them demonstrates that they are genetically distinct populations (Whitehead et al. 1992). It is possible that $2 \mathrm{~A}$ and $2 \mathrm{~B}$ are two separate races and might be distinguished by pathogenicity testing if the range of differential lines was extended; new line differential has been demonstrated recently for a sharper characterization race 2 Fusarium oxysporum f. sp. phaseoli (AlvesSantos et al. 2002). Generally, in various formae speciales all isolates of the same VCG are compatible with each other. In addition, some combinations between the race 1 isolates produced weak or partial reactions. These differences in the intensity of crop interactions have been reported in F. oxysporum and could reflect the result of the action of alleles at different loci affecting vegetative compatibility (Nogales Moncada et al. 2009). Moreover, some isolates in the VCG were incompatible; that is, two isolates might be vegetatively incompatible even though each is compatible with a $3 \mathrm{rd}$ isolate. Concerning vegetative compatibility in Verticillium dahliae, Rataj-Guranowska et al. (2016) observed bridges between American testers VCG 2 and VCG 4, also between American and Dutch testers and between subgroup testers VCG $2 \mathrm{~A}$ and 2B. The occurrence of these bridging strains is well known in F. oxysporum (Vakalounakis and Fragkiadakis 2004). Another difference between FOP and other formae speciales is demonstrated by the anomalies found in the pairings of race 1 isolates. The presence of two subgroups is not explained by geographical factors since isolates from both Europe and North America are present in the two subgroups (Whitehead et al. 1992). The weak complementation found between some race 1 and race 5 isolates even though they are in separate VCGs is not unique. Somrith (2011) reported that bridging isolates were capable of forming heterokaryons with isolates in both of two closely related VCGs in F. oxysporum f. sp. cubense. According to the analysis of Whitehead et al. (1992) it may be possible for weak complementation to occur in Fusarium oxysporum f. sp. pisi (FOP) even when two isolates differ slightly at one or more loci. Such differences could come about, for example,if a series of missense alleles of a particular het gene were present in the population. Some combinations might lead immediately to compatibility whereas others either would not or only do so after a long time, depending on the nature and position of the amino acid change (Nogales Moncada et al. 2009). This could explain both the variation found in race 1 and the weak compatibility between some isolates of race 1 and race 5 . Studies undertaken by different molecular techniques have made it possible to determine that races 1,5 and 6 are closely linked and that race 2 is distinct (Okubara et al. 2005; Sharma et al. 2006).

In this study, the complementation between pathogenic isolates FOP and nonpathogenic isolate FO was tested. The nonpathogenic isolate was vegetatively compatible with some isolates of races 1 and 6 . It was grouped in the same VCG as races 1 and 6, which includes pathogenic and nonpathogenic isolates. According to a study conducted by Nogales Moncada et al. (2009) on pathogenic and nonpathogenic isolates, most of the non-pathogenic isolates were compatible with a yellowing-type low virulent F. oxysporum f. sp. ciceris isolate, thus suggesting the possibility of the existence of transition isolates between pathogenic and nonpathogenic populations. Vegetative compatibility testing supported that F. oxysporum f. sp. betae is polyphyletic and that pathogenic isolates cannot be differentiated from nonpathogenic F. oxysporum using vegetative compatibility (Webb et al. 2013). Little is known, however, about the ecological significance and the population dynamics of the non-pathogenic strains of F. oxysporum, particularly at the subspecies level. Differentiating strains among the nonpathogenic F. oxysporum isolates is very important since they could provide a means of identifying and characterizing the various subpopulations of F. oxysporum. No specific relationship was observed between pathogenicity, VCGs and geographic origin of the isolates in this study. These results are in agreement with results from previous studies with other Fusarium spp. (Mohammadi and Mofrad 2009; Mohammadi et al. 2012) and on various formae speciales of F. oxysporum (Belabid and Fortas 2002).

\section{References}

Abo K., Klein KK., Edel-Hermann V., Gautheron N., Dossahoua T., Steinberg C. 2005. High genetic diversity among strains of Fusarium oxysporum f. sp. vasinfectum from cotton in Ivory Coast. Phytopathology 95 (12): 1391-1396. DOI: https://doi.org/10.1094/phyto-95-1391

Alves-Santos F.M., Martínez-Bermejo D., Rodríguez-Molina M.C., Díez J.J. 2007. Cultural characteristics, pathogenicity and genetic diversity of Fusarium oxysporum isolates from tobacco fields in Spain. Physiological and Molecular Plant Pathology 71 (1-3): 26-32. DOI: https://doi.o=rg/10.1016/j. pmpp.2007.09.007

Alves-Santos F.M., Cordeiro-Rodrigues L., Sayagués J.M., Martín-Domínguez R., García-Benavides P., Crespo M.C., 
Díaz-Mínguez J.M., Eslava A.P. 2002. Pathogenicity and race characterization of Fusarium oxysporum f. sp. phaseoli isolates from Spain and Greece. Plant Pathology 51 (5): 605-611. DOI: https://doi.org/10.1046/j.1365-3059 2002.00745.x

Baayen R.P., O’Donnell K., Bonants P.J.M., Cigelnik E., Kroon L.P.N.M., Roebroeck E.J.A., Waalwijk C. 2000. Gene genealogies and AFLP analyses in the Fusarium oxysporum complex identify monophyletic and nonmonophyletic formae speciales causing wilt and rot disease. Phytopathology 90 (8): 891-900. DOI: https://doi.org/10.1094/phyto.2000.90.8.891

Baysal Ö., Siragusa M., Gümrükcü E., Zengin S., Carimi F., Sajeva M. 2010. Molecular characterization of Fusarium oxysporum $\mathrm{f}$. sp. melongenae by ISSR and RAPD markers on eggplant. Biochemical Genetics 48 (5-6): 524-537. DOI: https://doi.org/10.1007/s10528-010-9336-1

Bayraktar H.H., Turkkan M., Dolar F.S. 2010. Characterization of Fusarium oxysporum f. sp. cepae from onion in Turkey based on vegetative compatibility and rDNA RFLP analysis. Journal of Phytopathology 158 (10): 691-697. DOI: https://doi.org/10.1111/j.1439-0434.2010.01685.x

Belabid L., Fortas Z. 2002. Virulence and vegetative compatibility of Algerian isolates of Fusarium oxysporum f. sp. lentis. Phytopathologia Mediterranea 41: 179-187.

Bowden R.L., Leslie J.F. 1992. Nitrate-nonutilizing mutants of Gibberella zeae (Fusarium graminearum) and their use in determining vegetative compatibility. Experimental Mycology 16 (4): 308-315. DOI: https://doi.org/10.1016/01475975(92)90007-e

Correll J.C., Klittich C.J.R., Leslie J.F. 1987. Nitrate nonutilising mutants of Fusarium oxysporum and the use in vegetative compatibility tests. Phytopathology 77 (12): 1640-1646. DOI: https://doi.org/10.1094/phyto-77-1640

Correll J.C. 1991. The relationship between formoe speciales, races and vegetative compatibility groups in Fusarium oxysporum. The American Phytopathology Society 81 (9): 1061-1064.

Cumagun J., Cumagun R., Zsachel O., Tolentino M., Relevante Ch., Balatero C. 2008. Vegetative compatibility among Fusarium oxysporum isolates from bitter gourd and bottle gourd in the Philippines. Journal of Plant Protection Research 48 (3): 283-293. DOI: https://doi.org/10.2478/ v10045-008-0037-2

Di Primo P., Cappelli C., Katan T. 2002. Vegetative compatibility grouping of Fusarium oxysporum $\mathrm{f}$. sp. gladioli from saffron. European Journal of Plant Pathology 108 (9): 869-875. DOI: https://doi.org/10.1023/A:1021204022787

Elena K., Pappas A.C. 2006. Race distribution, vegetative compatibility and pathogenicity of Fusarium oxysporum f. sp. melonis isolates in Greece. Journal of Phytopathology 154 (4): 250-255. DOI: https://doi.org/10.1111/j.1439-0434 2006.01099.x

Haglund W.A., Kraft J.M. 2001. Fusarium wilt. p. 13-14. In: "Compendium of Pea Diseases and Pests" (Kraft J.M., Pfleger F.L., eds.). American Phytopathological Society, St. Paul, USA, 67 pp.

Katan T., Katan J. 1999. Vegetative compatibility grouping in Fusarium oxysporum f. sp. radicis-lycopersici from the UK, the Netherlands, Belgium and France. Plant Pathology 48 (4): 541-549. DOI: https://doi.org/10.1046/j.1365-3059 $.1999 .00362 . \mathrm{x}$

Klein K.K., Edel-Hermann V., Gautheron N., Traore D., Steinberg C. 2005. High genetic diversity among strains of Fusarium oxysporum $\mathrm{f}$. sp. vasinfectum from cotton in Ivory Coast. Phytopathology 95 (12): 1391-1396. DOI: https:// doi.org/10.1094/phyto-95-1391

Leslie J.F. 1993. Fungal vegetative compatibility. Annual Review of Phytopathology 31 (1): 127-150. DOI: https://doi. org/10.1146/annurev.py.31.090193.001015

Lori G., Edel-Hermann V., Gautheron N., Alabouvette C. 2004. Genetic diversity of pathogenic and nonpathogenic populations of Fusarium oxysporum isolated from carnation fields in Argentina. Phytopathology 94 (6): 661-668. DOI: https://doi.org/10.1094/phyto.2004.94.6.661

Merzoug A., Belabid L., Youcef-Benkada M., Benfreha F., Bayaa B. 2014. Pea Fusarium wilt races in western Algeria. Plant Protection Sciences 50: 70-77.

Mohammadi A., Mofrad N.N. 2009. Genetic diversity in population of Fusarium solani from cumin in Iran. Journal of Plant Protection Research 49 (3): 283-286. DOI: https:// doi.org/10.2478/v10045-009-0045-x

Mohammadi A., Nejad R.F., Mofrad N.N. 2012. Fusarium verticillioides from sugarcane, vegetative compatibility groups and pathogenicity. Plant Protection Science 48 (3): 80-84.

Nagarajan G., Kang S.W., Nam M.H., Song J.Y., Yoo S.J., Kim H.G. 2006. Characterization of Fusarium oxysporum f. sp. fragariae based on vegetative compatibility group, random amplified polymorphic DNA and pathogenicity. Plant Pathology Journal 22 (3): 222-229. DOI: https://doi.org/10.5423/ ppj.2006.22.3.222

Nogales Moncada A.M., Jimenez Diaz M.R., Perez Artes E. 2009. Vegetative compatibility groups in Fusarium oxysporum f. sp. ciceris and F. oxysporum non-pathogenic to Chickpea. Journal of Phytopathology 15 (11-12): 729-735. DOI: https://doi.org/10.1111/j.1439-0434.2009.01562.x

Okubara P.A., Schroeder K.L., Paulitz T.C. 2005. Real-time polymerase chain reaction: applications to studies on soilborne pathogens. Canadian Journal of Plant Pathology 27 (3): 300-313. DOI: http://dx.doi.org/10.1080/07060660509507229

Pasquali M., Dematheis F., Gilardi G., Gullino M.L., Garibaldi A. 2005. Vegetative compatibility groups of Fusarium oxysporum f. sp. lactucae from lettuce. Plant Disease 89 (3): 237-240. DOI: https://doi.org/10.1094/pd-89-0237

Puhalla J.E. 1985. Classification of strains of Fusarium oxysporum on the basis of vegetative compatibility. Canadian Journal of Botany 63 (2): 179-183. DOI: https://doi.org/10.1139/b85020

Rataj-Guranowska M. 2016. An efficient method for selecting stable tester strains of vegetative compatibility groups in Verticillium dahliae. Journal of Plant Protection Research 56 (2): 163-166. DOI: https://doi.org/10.1515/jppr-2016-0028

Rodríguez-Molina C., Morales-Rodríguez C., Palo C., Osuna D., Iglesias J., García J.A. 2013. Pathogenicity, vegetative compatibility and RAPD analysis of Fusarium oxysporum isolates from tobacco fields in Extremadura. European Journal of Plant Pathology 136 (3): 639-650. DOI: https:// doi.org/10.1007/s10658-013-0194-7

Saabale P.R., Dubey S.C. 2014. Pathogenicity and vegetative compatibility grouping among Indian populations of Fusarium oxysporum f. sp. ciceris causing chickpea wilt. Phytoparasitica 42 (4): 465-473. DOI: https://doi.org/10.1007/ s12600-014-0383-8

Sharma P., Sharma K.D., Sharma R., Plaha P. 2006. Genetic variability in pea wilt pathogen Fusarium oxysporum f. sp. pisi in north western Himalayas. Indian Journal of Biotechnology (5): 298-302.

Somrith A., Singburaudom N., Piasai O. 2011. Vegetative compatibility groups of Fusarium oxysporum f. sp. cubense. Kasetsart Journal - Natural Science 45: 451-460.

Vakalounakis D.J., Wang Z., Fragkiadakis G.A., Skaracis G.N., Li D.B. 2004. Characterization of Fusarium oxysporum isolates obtained from cucumber in China by pathogenicity, VCG, and RAPD. Plant Disease 88 (6): 645-649. DOI: https://doi.org/10.1094/pdis.2004.88.6.645

Whitehead D.S., Coddington A., Lewis B.G. 1992. Classification of races by DNA polymorphism analysis and vegetative compatibility grouping in Fusarium oxysporum f. sp. pisi. Physiological and Molecular Plant Pathology 41 (4): 295-305. DOI: https://doi.org/10.1016/0885-5765(92)90028-t

Webb K.M., Case A.J., Brick M.A., Otto K., Schwartz H.F. 2013. Cross pathogenicity and vegetative compatibility of Fusarium oxysporum isolated from sugar beet. Plant Disease 97 (9): 1200-1206. DOI: http://dx.doi.org/10.1094/PDIS-11-12$-1051-\mathrm{RE}$ 